\title{
Corrosion-induced Microstructural Developments in 316 Stainless Steel during Exposure to Molten $\mathrm{Li}_{2} \mathrm{BeF}_{4}(\mathrm{FLiBe})$ Salt
}

Guiqiu Zheng ${ }^{1}$, Lingfeng $\mathrm{He}^{2}$, David Carpenter ${ }^{1}$, Kumar Sridharan ${ }^{3}$

${ }^{1}$ Nuclear Reactor Laboratory, Massachusetts Institute of Technology, Cambridge MA

${ }^{2}$ Idaho National Laboratory, Idaho Fall ID

${ }^{3}$ Department of Engineering Physics, University of Wisconsin-Madison, Madison WI

\begin{abstract}
The microstructural developments in the near-surface regions of AISI 316 stainless steel during exposure to molten $\mathrm{Li}_{2} \mathrm{BeF}_{4}(\mathrm{FLiBe})$ salt have been investigated with the goal of using this material for the construction of the fluoride salt-cooled high-temperature reactor (FHR), a leading nuclear reactor concept for the next generation nuclear plants (NGNP). Tests were conducted in molten FLiBe salt (melting point: $459^{\circ} \mathrm{C}$ ) at $700^{\circ} \mathrm{C}$ in graphite crucibles and 316 stainless steel crucibles for exposure duration of up to 3000 hours. Corrosion-induced microstructural changes in the near-surface regions of the samples were characterized using scanning electron microscopy (SEM) in conjunction with energy dispersive x-ray spectroscopy (EDS) and electron backscatter diffraction (EBSD), and scanning transmission electron microscopy (STEM) with EDS capabilities. Intergranular corrosion attack in the near-surface regions was observed with associated $\mathrm{Cr}$ depletion along the grain boundaries. High angle grain boundaries $\left(15-180^{\circ}\right)$ were particularly prone to intergranular attack and $\mathrm{Cr}$ depletion. The depth of attack extended to the depths of $22 \mu \mathrm{m}$ after 3000-hour exposure for the samples tested in graphite crucible, while similar exposure in 316 stainless steel crucible led to the attack depths of only about $11 \mu \mathrm{m}$. Testing in graphite crucibles led to the formation of nanometer-scale $\mathrm{Mo}_{2} \mathrm{C}, \mathrm{Cr}_{7} \mathrm{C}_{3}$ and $\mathrm{Al}_{4} \mathrm{C}_{3}$ particle phases in the near-surface regions of the material. The copious depletion of $\mathrm{Cr}$ in the near-surface regions induced a $\gamma$ martensite to $\alpha$-ferrite phase $\left(\mathrm{FeNi}_{\mathrm{x}}\right)$ phase transformation. Based on the microstructural analysis, a thermal diffusion controlled corrosion model was developed and experimentally validated for predicting long-term corrosion attack depth.
\end{abstract}

Keywords: nuclear reactor; 316 stainless steel; molten salt; microstructure; corrosion

\section{Introduction}

Materials corrosion is among the most significant challenges in current and proposed nuclear energy systems and its effects become particularly important for operation to longer lifetimes and higher operating temperatures [1]-[5]. This problem is of particular concern in the fluoride salt-cooled high-temperature nuclear reactor (FHR) which is emerging as a leading reactor concept for the next generation nuclear plants because of many attractive benefits and the successes of the molten salt reactor experiment (MSRE) program at the Oak Ridge National Laboratory (ORNL) in 1950s-70s [1], [4], [6]-[11]. The present FHR design calls for the use of molten FLiBe salt as primary coolant with tristructural-isotropic (TRISO) fuel pebbles submerged in this coolant. The use of molten salt as coolant offers a number of potential benefits such as high thermal efficiency, atmospheric pressure 
operation, low spent fuel per unit energy, and high degree of passive safety [8], [12]-[14]. FLiBe in particular has been selected on account of its neutronic efficiency and its relatively low melting point and high boiling point $\left(1430^{\circ} \mathrm{C}\right) .316$ stainless steel is being actively considered for the construction of the FHR vessel and other structural components because of its ASME code certification status up to the FHR outlet temperature of $700^{\circ} \mathrm{C}$ [8], [15]-[17]. Additionally, data on the corrosion of this alloy exists from the thermal convection loop studies performed in the MSRE program [18], [19]. However, the corrosion data from these earlier ORNL experiments relied on weight change measurements, which implicitly assumes uniform corrosion and optical microscopy performed in this earlier study did not provide the required resolution for imaging required to elicit the mechanisms of corrosion.

Nuclear graphite has also been selected as a structural material for the reactor core in the FHR because of its outstanding high temperature properties and its relatively good inertness to molten fluoride salts. However, the presence of graphite has been shown to adversely affect the corrosion of metallic materials in molten fluoride salts. For example, Olson et al. reported that Inconel-800H lost more weight due to corrosion in graphite container than when tested in other metallic containers in molten FLiNaK salt at $850^{\circ} \mathrm{C}$ [20]. Sellers et al. also observed that the presence of graphite led to more aggressive corrosion in metallic materials such as stainless steel and Hastelloy $\mathrm{N}$ in Zr-reduced FLiNaK salt [21]

With the above background, the present work was aimed at developing a fundamental understanding of longterm corrosion of 316 stainless steel in molten FLiBe salt at $700^{\circ} \mathrm{C}$ in both 316 stainless steel and graphite crucibles for exposure duration of up to 3000 hours. The microstructural developments in the near-surface regions of 316 stainless steel due to corrosion have been characterized by SEM, $\mathrm{x}$-ray diffraction, and TEM, and this information has been used to develop a model for predicting the long-term performance of 316 stainless steel in high-temperature molten FLiBe salt for FHR applications.

\section{Experimental}

\subsection{Materials}

The nominal composition of 316L (low carbon) stainless steel sheet used in this study is shown in Table 1. The sheet stock of this material procured from a commercial vendor was sectioned to $\sim 1 \mathrm{~mm} \times 7 \mathrm{~mm} \times 13 \mathrm{~mm}$ size and a hole ( $\sim \mathrm{mm}$ in diameter) was drilled in these samples to facilitate their suspension in molten salt with a 316 stainless steel wire. The sample surfaces were mechanically polished to a 1200-grit final finish with silicon-carbide paper, and cleaned with deionized water and acetone prior to corrosion tests.

Table 1: Nominal chemical composition of 316 stainless steel (wt.\%) used in this study.

\begin{tabular}{lllllllllll}
\hline $\mathrm{Fe}^{*}$ & $\mathrm{Cr}$ & $\mathrm{Cu}$ & $\mathrm{Mn}$ & $\mathrm{Mo}$ & $\mathrm{N}$ & $\mathrm{Ni}$ & $\mathrm{P}$ & $\mathrm{S}$ & $\mathrm{Si}$ & $\mathrm{C}$ \\
\hline 68.8134 & 16.825 & 0.3795 & 1.5305 & 2.0115 & 0.051 & 10.025 & 0.031 & 0.0016 & 0.309 & 0.0225 \\
\hline * balance & & & & & & & & & &
\end{tabular}


${ }^{7} \mathrm{Li}$-enriched FLiBe salt used for this study was provided by ORNL. This salt was re-melted and further purified by sparging with a $\mathrm{H}_{2}-\mathrm{HF}$ gas mixture for the present study. The details of the purification process have been described previously [15], [22], [23].

\subsection{Corrosion Tests}

The crucibles for the tests were prepared from a high purity nuclear graphite cylinder (IG-110U, Toyo Tanso Co., Ltd, Japan). Six cylindrical compartments (10.3 $\mathrm{mm}$ in diameter and $146 \mathrm{~mm}$ in depth) were machined in the crucible. The crucible was cleaned and baked at $850^{\circ} \mathrm{C}$ in $10 \%$ hydrogen environment to remove any trace moisture or graphite powder residue left from the machining process. A 316 stainless steel welded liner was inserted into some of these compartments in effect providing for 316 stainless steel containers for the tests. The aforementioned purified FLiBe salt was melted and transferred into each compartment through a specially designed dripping system made of nickel, following which the 316 stainless steel samples were loaded into molten salt. The graphite crucible was then transferred into a ceramic furnace (DS Fibertech Corporation, United States) in a glove box to initiate corrosion tests at $700^{\circ} \mathrm{C}$. During corrosion tests, the moisture and oxygen levels in the glove box were monitored online and maintained below $0.7 \mathrm{ppm}$ and $10 \mathrm{ppm}$, respectively. The test samples were removed from the molten salt at intervals of 1000 hours, 2000 hours and 3000 hours. After removal, the samples were left to cool in the glove box and then cleaned in deionized water for subsequent microstructural analysis. The post-corrosion samples' surface was plated with a $\mathrm{Cu}$ layer to preserve the edges from getting rounded during sample preparation.

\subsection{Post-corrosion Examinations}

The weight change (per unit area) of samples as a measure of corrosion was measured using a precision balance of resolution of $0.001 \mathrm{mg}$, see details in reference [15]. Following this, the microstructural changes in the near-surface regions of the samples due to corrosion were evaluated using scanning electron microscopy (LEO 1530), energy dispersive x-ray spectroscopy (EDS), electron backscatter diffraction (EBSD), and scanning transmission electron microscopy (STEM, Titan, FEI).

The near-surface regions of the samples were characterized using SEM with particular emphasis on the grain boundaries and new-formed precipitate phases. The microstructure underneath surface was examined by analyzing the corrosion layer in cross-section also using SEM in conjunction with EDS and EBSD. The parameters for the EDS x-ray line scans and spectral imaging were 100 scan points with 5 scans and 50 frames with 10 seconds frame time, respectively. A sample tested for 1000 hours in graphite crucible was selected for EBSD analysis. The EBSD analysis focused on a region where EDS maps were collected in order to study the correlations between matrix phases and elemental compositions in that region. Prior to collecting EBSD data $\alpha$ and $\gamma$ phases of Fe were pre-loaded into TSL orientation imaging microscopy (OIM, TexSEM Laboratory, Inc.) data collection system for identifying the distribution of these two phases. Following the procedures of TSLOIM data analysis [24]-[26], the original EBSD data was refined and the information of grain size distribution, grain orientation, phase distribution as well as grain boundary character distribution was acquired. A 3000-hour 
exposed sample tested in graphite crucible was selected for STEM-EDS analysis. Focused ion beam (FIB, ZEISS 1540XB CrossBeam) milling technique was used to prepare TEM lamella samples. The corrosion surface was protected by Pt layer deposited prior to ion milling. Using this technique, a FIB lift-out samples measuring 20 $\mu \mathrm{m}$ in width, $2 \mu \mathrm{m}$ in thickness and $15 \mu \mathrm{m}$ in depth were lifted out from an area where the grain boundary was deeply attacked. Both sides of this lift-out sample were further milled to electron transparency using the FIB. The final thickness of this FIB lamella was about $100 \mathrm{~nm}$. Following this, the morphology and composition of nanosized precipitates, grain boundaries, carbide phases, and matrix in the near-to-surface regions were identified using the STEM equipped with a high-angle annular dark-field (HAADF) detector and an EDS system.

\section{Results and Discussion}

\subsection{Microstructure of the surface after corrosion tests}

As shown in Figure 1, the 316 stainless steel samples' surface was noticeably attacked by the molten FLiBe salt for tests performed in both 316 stainless steel and graphite crucibles. In addition to the typical intergranular corrosion, some spherical Mo-rich particles $\left(\mathrm{MoSi}_{2}\right.$ identified by XRD [15]) were observed to form on the corrosion surface. The grain boundaries on the surface of the sample tested in graphite crucible (Figure 1(c)) appeared to have been attacked to greater depth than those tested in 316 stainless steel crucibles (Figure 1(b)). This suggests that the presence of graphite in the molten FLiBe salt accelerates the corrosion of 316 stainless steel. The effect of the graphite container on the driving force for corrosion will be discussed in subsequent sections.

\subsection{Cross-sectional microstructure after corrosion tests}

The cross-sectional SEM images of pre- and post-corrosion 316 stainless steel samples are shown in Figure 2. Figure 2(a) for the sample before the corrosion tests shows a relatively smooth surface with a uniform microstructure. After 3000-hour exposures (Figure 2(b) and 2(c), respectively) in 316 stainless steel crucibles precipitates are observed to form along the grain boundaries. Figure 2(c) shows numerous nanometer scale precipitate particles randomly distributed in the alloy matrix. The crystal structure and chemical compositions of the precipitate particles in the near-surface regions were further identified by the STEM-EDS analysis.

Quantitative elemental analysis and $\mathrm{Cr}$ distribution in the near-surface regions of the 316 stainless steel samples tested in the two crucible materials are presented in the EDS profiles and $\mathrm{Cr}$ maps in Figure 3. The EDS $\mathrm{Cr}$ maps clearly show preferential $\mathrm{Cr}$ depletion along grain boundaries for both types of post-corrosion samples. However, the maximum $\mathrm{Cr}$ depletion depth in the sample tested in graphite crucible $(\sim 22 \mu \mathrm{m})$ is about two times higher than those tested in 316 stainless steel crucible $(\sim 11 \mu \mathrm{m})$ after 3000-hour tests. The quantitative $\mathrm{Cr}$ profiles are in agreement with the EDS maps and the microstructure of the corrosion-affected surface (Figure 3(a) and Figure 3(b)). Moreover, a plateau ([Cr] 8\%) was observed in the $\mathrm{Cr}$ profiles which corresponds to the adjacent bulk grain in the corrosion-affected region. It is clear from these observations that the presence of 
graphite results in the so called "dissimilar materials corrosion" wherein 316 stainless steel corrodes anodically with respect to graphite.

$\mathrm{Cr}$ outward diffusion is the main mechanism driving $\mathrm{Cr}$ depletion from alloy during corrosion in hightemperature molten salt. The plateau $(\sim 8 \%)$ in the $\mathrm{Cr}$ profiles (Figure 3(b)) indicates the occurrence of $\mathrm{Cr}$ depletion from the bulk grains that are adjacent to surface. This is a result of the relatively lower thermal diffusion coefficient of $\mathrm{Cr}$ in grains $\left(\mathrm{D}_{\mathrm{Cr} / 316 \mathrm{ssGrain}}=9 \times 10^{-19} \mathrm{~m}^{2} / \mathrm{sec}\right)$ compared to grain boundaries $\left(\delta \mathrm{D}_{\mathrm{Cr} / 316 \mathrm{ssGB}}=9 \times 10^{-23}\right.$ $\mathrm{m}^{3} / \mathrm{sec}$, assuming grain boundary width $\delta=0.5 \mathrm{~nm}$ ) at $700^{\circ} \mathrm{C}$ [27], [28]. Thus the thermal diffusion of $\mathrm{Cr}$ through both bulk grains and grain boundaries determine the $\mathrm{Cr}$ depletion rate from alloy.

Figure 4 shows a series of EDS elemental maps and EBSD maps in a near-surface regions of the samples exposed for 1000 hours in a graphite crucible. The cross-sectional SEM image (Figure 4(a)) shows distinguishable grains and grain boundaries. The EDS elements maps show that the $\mathrm{Cr}$ is greatly depleted in a narrow layer near the surface and some grain boundaries where $\mathrm{Fe}$ and $\mathrm{Ni}$ concentrations are relatively higher than in the matrix. The distribution and orientation of each single grain in this region is presented in EBSD grain map (Figure 4(e)) and inverse polar figure (IPF) (Figure 4(f)). More importantly, the $\alpha$ phase and grain boundary distribution in this area are identified in Figure 4(g) and (h). Combining the EDS and EBSD results, it appears that an approximately $2 \mu \mathrm{m}$ thin layer of $\alpha$ phase formed underneath corrosion surface and the $\alpha$ phase extended to about $15 \mu \mathrm{m}$ in depth along certain high angle grain boundaries (15-180 ${ }^{\circ}$, blue lines). Higher concentrations of $\mathrm{Fe}$ and $\mathrm{Ni}$ but almost no $\mathrm{Cr}$ was measured in the $\alpha$ phase where fractional $\gamma$ phase coexists. Additionally, the EBSD grain boundary maps show that the $\mathrm{Cr}$ depletion and phase transformation largely occurred along high angle grain boundaries and coherent $\Sigma 3$ grain boundaries (orange lines) were very resistant to the $\mathrm{Cr}$ depletion.

The substantial Cr depletion also induced phase transformation (Figure 4(g)). With the progress of corrosion, $\mathrm{Cr}$ continuously depletes from alloy resulting in a thin layer where $\mathrm{Cr}$ is absent. This thin layer undergoes a phase transformation from $\gamma$-martensite phase to the $\alpha$-ferrite phase at $700^{\circ} \mathrm{C}$. Moreover, the $\alpha$-ferrite phase only developed along high angle grain boundaries where the $\mathrm{Cr}$ was massively depleted. Differently, the coherent $\Sigma 3$ grain boundaries show remarkable stability with respect to the high temperature corrosion[29]. This finding implies that the corrosion resistance of 316 stainless steel in molten FLiBe salt can be improved through a grain boundary engineering.

\subsection{Carbide phase formation in the near-surface regions of the stainless steel}

The microstructural features in the near-surface regions of the 316 stainless steel sample tested in FLiBe salt in graphite crucible for 3000 hours was further characterized in details at nanometer scale, as shown in Figure 5 STEM images. A large number of randomly distributed carbides particles with various morphologies were observed, in addition to the $\mathrm{MoSi}_{2}$ particles ( $300 \mathrm{~nm}$ in diameter) on surface and grain boundary precipitates. Figure 5(b) focuses on a local area in Figure 5(a) for observing the fine details underneath corrosion surface, such as grain boundaries, spherical particles (black), and sub-grains. Figure 5(c) focuses on another local region in Figure 5(a) which includes three differently shaped particles, namely, spherical particles (1), hexagonal- 
shaped particles (2), and needle-shaped particles (3). Figure 5(d) distinctly shows the grain boundary precipitates (mainly $\mathrm{M}_{23} \mathrm{C}_{6}$ and $\mathrm{M}_{7} \mathrm{C}_{3}$ ) in a triple grain boundary junction. The thickness of the grain boundary precipitates was on the order of $10 \mathrm{~nm}$.

Figure 6 shows the STEM-EDS spectra of the phases labeled in Figure 5(c) as 1, 2, 3 and 4 for identifying the main chemical compositions of each phase. In addition to the high Fe concentration in phase 4 of the alloy matrix, the EDS spectra show high concentration of $\mathrm{Mo}, \mathrm{Cr}$ and $\mathrm{Al}$ element corresponding to phase $1\left(\mathrm{Mo}_{2} \mathrm{C}\right), 2\left(\mathrm{Cr}_{7} \mathrm{C}_{3}\right)$ and $3\left(\mathrm{Al}_{4} \mathrm{C}_{3}\right)$, respectively. The signal of $\mathrm{Cu}$ on each spectrum is from $\mathrm{Cu}$ grid. The $\mathrm{O}$ detected on phase 3 is likely due to the hydrolysis of $\mathrm{Al}_{4} \mathrm{C}_{3}+12 \mathrm{H}_{2} \mathrm{O}=4 \mathrm{Al}(\mathrm{OH})_{3}+3 \mathrm{CH}_{4}$ at room temperature while exposing FIB lamella to air.

The above observations suggest that in addition to promoting accelerated dissolution of $\mathrm{Cr}$ in the alloy, carbon particles released from the graphite surface can deposit on the surface of stainless steel and potentially diffuse into the near-surface regions to form fine size-scale thermodynamically stable carbide phases. The data on Gibbs free energy of carbides formation $(\Delta G)$ at $700^{\circ} \mathrm{C}$ (Eq. 1, 2 and 3) supports the formation of these carbide phases within the 316 stainless steel.

$$
\begin{array}{ll}
2 \mathrm{Mo}+\mathrm{C} \rightarrow \mathrm{Mo}_{2} \mathrm{C} ; \Delta G_{a t 700^{\circ} \mathrm{C}}=-54.55 \mathrm{~kJ} / \mathrm{mole} & \text { Eq. } 1 \\
\frac{7}{3} \mathrm{Cr}+\mathrm{C} \rightarrow \frac{1}{3} \mathrm{Cr}_{7} C_{3} ; \Delta G_{a t} 700^{\circ} \mathrm{C}=-58.57 \mathrm{~kJ} / \mathrm{mole} & \text { Eq. } 2 \\
\frac{4}{3} \mathrm{Al}+\mathrm{C} \rightarrow \frac{1}{3} \mathrm{Al}_{4} \mathrm{C}_{3} ; \Delta G_{a t 700^{\circ} \mathrm{C}}=-57.44 \mathrm{~kJ} / \mathrm{mole} & \text { Eq. } 3
\end{array}
$$

The inward diffusion distance of the carbon determines the maximum depth of these chemical reactions within alloy which depends on the temperature. Since the chromium carbides are stable in molten fluoride salts, this newly formed carbide phase particles play an important role in the long-term corrosion behavior of 316 stainless steel in molten FLiBe salt, by deterring the dissolution of Cr into the molten salt while also serving as a barrier to protect alloy from further corrosion attack. Based on the above experimental observations, Figure 7 schematically illustrates the corrosion mechanisms of 316 stainless steel in molten FLiBe salt in the two crucible materials. In the 316 stainless steel crucible, the $\mathrm{Cr}$ (yellow) in the near-surface regions of the alloy migrates directly towards the surface or diffuses to the grain boundaries and then to the surface via the grain boundaries. On the alloy surface, the $\mathrm{Cr}$ reacts with fluorine ions and then dissolves into molten salt by a fluorination process. Thus, the extent of $\mathrm{Cr}$ fluorination is dictated by both the thermal diffusion rate of $\mathrm{Cr}$ through the alloy and the redox potential of molten salt (concentration of $\mathrm{F}^{-}$). In graphite crucible tests, the molten salt contains carbon particles (denoted in black) that are originally liberated from graphite crucible wall. The carbon permeates through molten salt medium and reacts with surface $\mathrm{Cr}$ in the alloy to form chromium carbide particles (red triangle) on the corrosion surface. Simultaneously, $\mathrm{Cr}$ is also partially fluorinated as $\mathrm{CrF}_{2}$ dissolving into molten salt. The excess carbon on the alloy surface continually diffuses into alloy matrix to react with the $\mathrm{Cr}$ (or $\mathrm{Mo}, \mathrm{Al}$ ) within alloy to form nanometer-scale carbide phases. The faster inward diffusion rate of carbon through 316 
stainless steel $\left(D_{\mathrm{C} / 316 s s}=10^{-15} \mathrm{~m}^{2} / \mathrm{s}\right.$ at $\left.700^{\circ} \mathrm{C}\right)$ compared to the outward diffusion of $\mathrm{Cr}$ in the alloy $\left(\mathrm{D}_{\mathrm{Cr} / 316 \mathrm{ss}}=10^{-20}\right.$ $\mathrm{m}^{2} / \mathrm{s}$ at $700^{\circ} \mathrm{C}$ ) [27], [30], [31] results in thicker carbide layer with increasing corrosion time. The formation of chromium carbides within alloy matrix appears to stabilize the chromium.

\subsection{Long-term corrosion prediction and validation}

Based on previous literature, the corrosion attack distance is generally expressed in terms of the depth of $\mathrm{Cr}$ depletion in Cr-containing alloys in high-temperature molten fluoride salt [15], [32], [33]. Under the assumption of $\mathrm{Cr}$ diffusion controls corrosion rate, the effective diffusion coefficient $\left(\mathrm{D}_{\text {eff }}\right)$ of $\mathrm{Cr}$ through alloy matrix can be obtained from the following equation [22], [32]:

$$
\mathrm{W}_{0}-\mathrm{W}_{1}=2 \mathrm{~S}_{0} \mathrm{C}_{0, \mathrm{Cr}} \sqrt{\frac{\mathrm{D}_{\text {eff }}}{\pi}}
$$

where $\mathrm{W}_{0}$ and $\mathrm{W}_{1}$ is the weight of pre-corrosion and post-corrosion sample, $\mathrm{S}_{0}$ is the surface area of the test sample prior to corrosion, $\mathrm{C}_{0, \mathrm{Cr}}$ is the initial $\mathrm{Cr}$ concentration in as-received 316 stainless steel, and $\mathrm{t}$ is corrosion time.

As discussed previously, the weight loss of alloy results mainly from $\mathrm{Cr}$ depletion from alloy matrix and therefore the effective diffusion coefficient $\left(D_{\text {eff }}\right)$ can be calculated using Eq. 4 to be $4.2 \times 10^{-19} \mathrm{~m}^{2} / \mathrm{s}$ for the 316 stainless steel tested in molten $\mathrm{FLiBe}$ at $700^{\circ} \mathrm{C}$.

Using the calculated $\mathrm{D}_{\text {eff }}$ value the $\mathrm{Cr}$ depletion profiles in the near-surface regions of the tested 316 stainless steel samples can be calculated by using a solution of Fick's second law, as follow [22]:

$$
\mathrm{C}_{\mathrm{Cr}}(\mathrm{x}, \mathrm{t})=\mathrm{C}_{0, \mathrm{Cr}} \operatorname{erf}\left(\frac{\mathrm{x}}{2 \sqrt{\mathrm{D}_{\text {eff }}}}\right)
$$

where $\mathrm{x}$ is the distance from alloy surface.

By substituting above calculated $D_{\text {eff }}$ into Eq. 5, the Cr concentration profiles $\mathrm{C}_{\mathrm{Cr}}(\mathrm{x}, \mathrm{t})$ of 316 stainless steel in molten salt for $\mathrm{t}=1000,2000,3000$ hours and 365 days were obtained, as shown in Figure 8.

To validate the calculation, the experimental $\mathrm{Cr}$ concentration profiles in the near-surface regions were extracted from the EDS Cr maps. Using the line-scan extraction function of Thermo Scientific NSS software, the elemental transitions from corrosion surface to the substrate on the acquired cross-sectional EDS images were analyzed. The thickness value (as a percentage of the EDS image size) of the extraction line was specified to $70 \%$ to homogenize the $\mathrm{Cr}$ concentration in same depth. This method eliminates the influence of preferential $\mathrm{Cr}$ depletion along grain boundaries and precipitates on the overall $\mathrm{Cr}$ concentration profiles. As shown in Figure 9, there is good agreement between the experimental profile and the calculated profile for 3000-hour corrosion testing, thus successfully validating this model. As a consequence, the corrosion attack depth is expected to be about $16 \mu \mathrm{m}$ for the 316 stainless steel in molten $\mathrm{FLiBe}$ salt at $700^{\circ} \mathrm{C}$ for one year, without graphite effect. Since the corrosion mechanism of the 316 stainless steel in graphite crucible is complicated, this model must be modified for predicting the corrosion attack depth for the alloy in the graphite corrosion system.

\section{Conclusion}


The microstructural evolution in the near-surface region of 316 stainless steel during exposure to molten FLiBe salt at $700^{\circ} \mathrm{C}$ has been investigated with the goal of using this material for structural components in the fluoride salt-cooled high-temperature reactor (FHR). Tests were performed in both 316 stainless steel and graphite crucibles. Intergranular corrosion was clearly observed with associated depletion of $\mathrm{Cr}$ in the nearsurface regions of the alloy which caused the formation of Mo-rich phase on corrosion surface. Cr depletion was more pronounced along high angle grain boundaries $\left(15-180^{\circ}\right)$. In terms of the depth of attack and $\mathrm{Cr}$ depletion corrosion was more pronounced in the samples tested in graphite crucible due to galvanic effects or dissimilar materials corrosion. The stainless steel samples tested in graphite crucible also exhibited carbide phase formation such as $\mathrm{Mo}_{2} \mathrm{C}, \mathrm{Cr}_{7} \mathrm{C}_{3}$ and $\mathrm{Al}_{4} \mathrm{C}_{3}$ in the form of nanometer sized particles in the near-surface regions due to the release of free carbon from the graphite surface into the salt and its migration to stainless steel surface. Surface de-alloying induced the phase transformation from $\gamma$-martensite to $\alpha$-ferrite phase in a thin layer underneath surface and this occurred predominantly at high angle grain boundaries. Coherent $\Sigma 3$ grain boundaries showed remarkable resistance to the $\mathrm{Cr}$ depletion.

Based on the understanding of the microstructural evolution of tested alloy, a thermal diffusion-controlled corrosion model was developed for predicting long-term corrosion attack depth. This model was validated by the experimental result of 3000-hour corrosion tested sample. Using the model, the maximum corrosion attack depth for 316 stainless steel in high-temperature molten FLiBe salt for one year $(\sim 16 \mu \mathrm{m})$ is predicted, in the absence of graphite.

\section{Acknowledgements}

This research is financially supported by the U.S. Department of Energy Nuclear Energy University Program Contract No. DE-AC07-05ID14517.

\section{References}

[1] S.J. Zinkle, G.S. Was, Acta Mater. 61(3) (2013) 735-758.

[2] S.J. Zinkle, J.T. Busby, Mater. Today 12(11) (2009) 12-19.

[3] T. Allen, J. Busby, M. Meyer, D. Petti, Mater. Today 13(12) (2010) 14-23.

[4] T.R. Allen, K. Sridharan, L. Tan, W.E. Windes, J.I. Cole, D.C. Crawford, G.S. Was, Nucl. Technol.162(3) (2008) 342-357.

[5] P. Yvon, F. Carré, J. Nucl. Mater. 385(2) (2009) 217-222.

[6] T.R. Allen, S. Ball, E. Blandford, T. Downar, G. Flanagan, C.W. Forsberg, E. Greenspan, D. Holcomb, L.W. Hu, R. Matzie, et al., White Paper of FHR Integrated Research Project Workshop 1, Technical Report, University of California, Berkeley, 2012.

[7] C.W. Forsberg, P.F. Peterson, P.S. Pickard, Nucl. Technol. 144(3) (2003) 1-25.

[8] G.F. Flanagan, D.E. Holcomb, S.M. Cetiner, FHR Generic Design Criteria, ORNL/TM-2012/226, Technical Report, Oak Ridege National Laboratory, 2012.

[9] R.C. Robertson, MSRE Design and Operations Report : Part I - Description of Reactor Design, ORNLTM-728, Technical Report, Oak Ridege National Laboratory, 1965. 
[10] C. Wong, B. Merrill, Relevant MSRE and MSR Experience, Technical Report, ITER TBM Project Meeting at University of California, Los Angeles, 2004.

[11] W.R. Grimes, Nucl. Appl. Technol. 8 (1970) 137-155.

[12] S. Delpech, C. Cabet, C. Slim, G.S. Picard, Mater. Today 13(12) (2010) 34-41.

[13] D.F. Williams, K.T. Clarno, Nucl. Technol. 163(3) (2008) 330-343.

[14] V. Khokhlov, V. Ignatiev, V. Afonichkin, J. Fluor. Chem. 130(1) (2009) 30-37.

[15] G. Zheng, B. Kelleher, G. Cao, M. Anderson, T. Allen, K. Sridharan, J. Nucl. Mater. 461(2015) 143-150.

[16] T.R. Allen, G. Kohse, M.H. Anderson, R. Matzie, R. Ballinger, M. Memmott, T. Burchell, J. Nestell, E. Blandford, et al., White Paper of FHR Integrated Research Project Workshop 3, Technical Report, University of California, Berkeley, 2012

[17] ASME Boiler \& Pressure Vessel Code, Section III, Rules for construction of nuclear facility components, Division 5, High temperature reactors, 2015th ed. New York, American Society of Mechanical Engineers, 2015.

[18] J.R. Keiser, J.H. DeVan, E.J. Lawrence, J. Nucl. Mater. 86(1979) 295-298.

[19] J.R. Keiser, J.H. DeVan, D.L. Manning, The Corrosion Resistance of Type 316 Stainless $\mathrm{Steel}_{\text {to }} \mathrm{Li}_{2} \mathrm{BeF}_{4}$, ORNL/TM-5782, Technical Report, Oak Ridege National Laboratory, 1977.

[20] L.C. Olson, R.E. Fuentes, M.J. Martinez-Rodriguez, J.W. Ambrosek, K. Sridharan, M.H. Anderson, B.L. Garcia-Diaz, J. Gray, T.R. Allen, ASME J. Sol. Energy Eng. 137(061007) (2015)1-8

[21] R.S. Sellers, W.J. Cheng, M.H. Anderson, K. Sridharan, C.J. Wang, T.R. Allen, Materials corrosion in molten LiF-NaF-KF eutectic salt under different reduction-oxidation conditions, in Proceedings of ICAPP, 2012.

[22] G. Zheng, B. Kelleher, L. He, G. Cao, M. Anderson, T. Allen, K. Sridharan, Corrosion 71(10) (2015)1257-1266.

[23] B. Kelleher, G. Zheng, M. Anderson, K. Sridharan, G. Cao, Purification of Non Uranium Bearing Fluoride Salts for Nuclear Applications, in Transactions of the American Nuclear Society, 109(1971) (2013) 10791081.

[24] L. Tan, X. Ren, K. Sridharan, T.R. Allen, Corros. Sci. 50(11) (2008) 3056-3062.

[25] Y. Palizdar, R.C. Cochrane, R. Brydson, R. Leary, A.J. Scott, J. Phys. Conf. Ser. 241 (2010) 012104.

[26] T.G. Woodcock, O. Gutfleisch, Acta Mater. 59(3) (2011) 1026-1036.

[27] A.F. Smith, Met. Sci, 9(1) (1975) 375-378.

[28] M. Mizouchi, Y. Yamazaki, Y. Iijima, K. Arioka, Mater. Trans. 45(10) (2004) 2945-2950.

[29] C. Hu, S. Xia, H. Li, T. Liu, B. Zhou, W. Chen, N. Wang, Corros. Sci. 53(5) (2011) 1880-1886.

[30] R. Braun, M. Feller-Kniepmeier, Phys. Stat. Sol. 90(2) (1985) 553-561.

[31] R.P. Agarwala, M.C. Naik, M.S. Anand, A.R. Paul, J. Nucl. Mater. 36(1970) 41-47.

[32] J.H. DeVan, R.B. Evans, Corrosion behavior of reactor materials in fluoride salt mixtures, ORNL-TM0328, Technical Report, Oak Ridege National Laboratory, 1962.

[33] J.W. Koger, Corrosion, 30(4) (1974) 125-130. 
Figure Captions

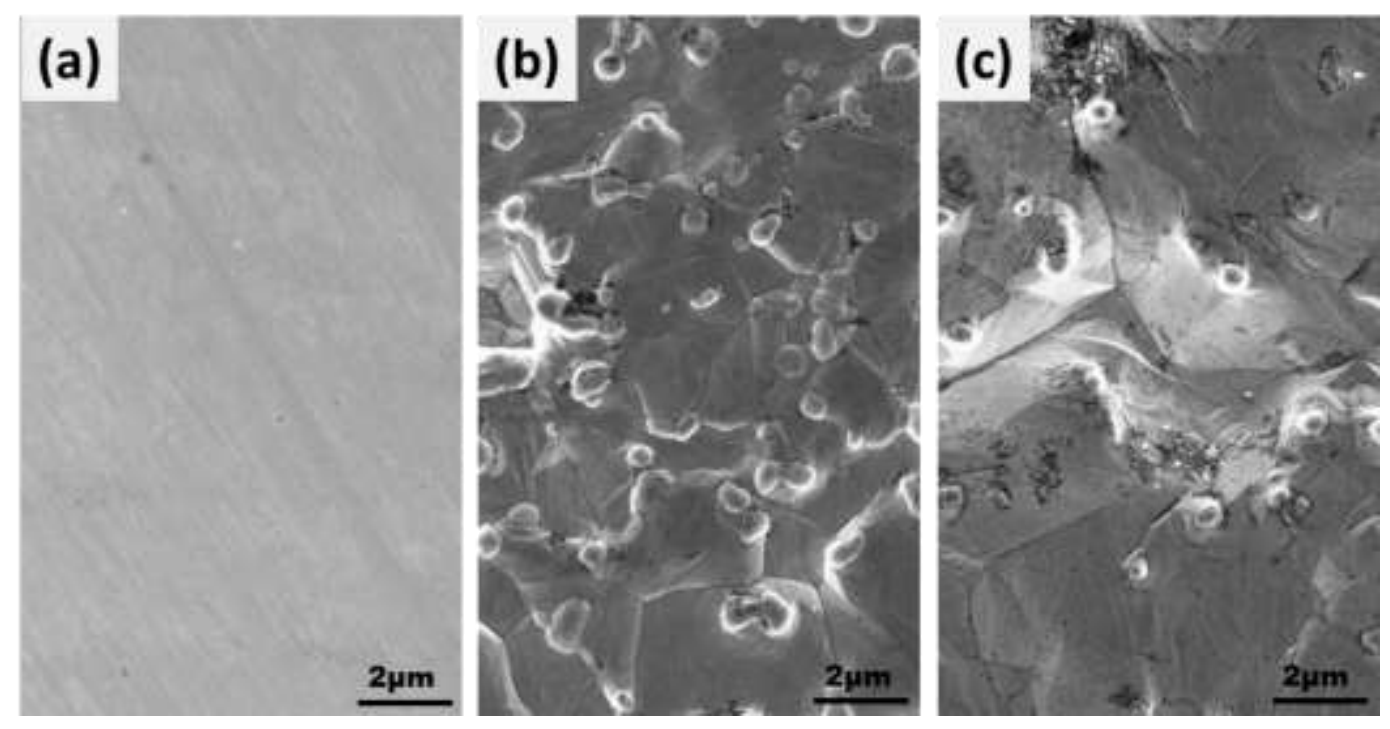

Figure 1: SEM images of (a) as-polished 316 stainless steel surface before corrosion tests, (b) and (c) the sample surface after 3000-hour exposure to molten FLiBe salt in 316 stainless steel crucible and in graphite crucible, respectively. 

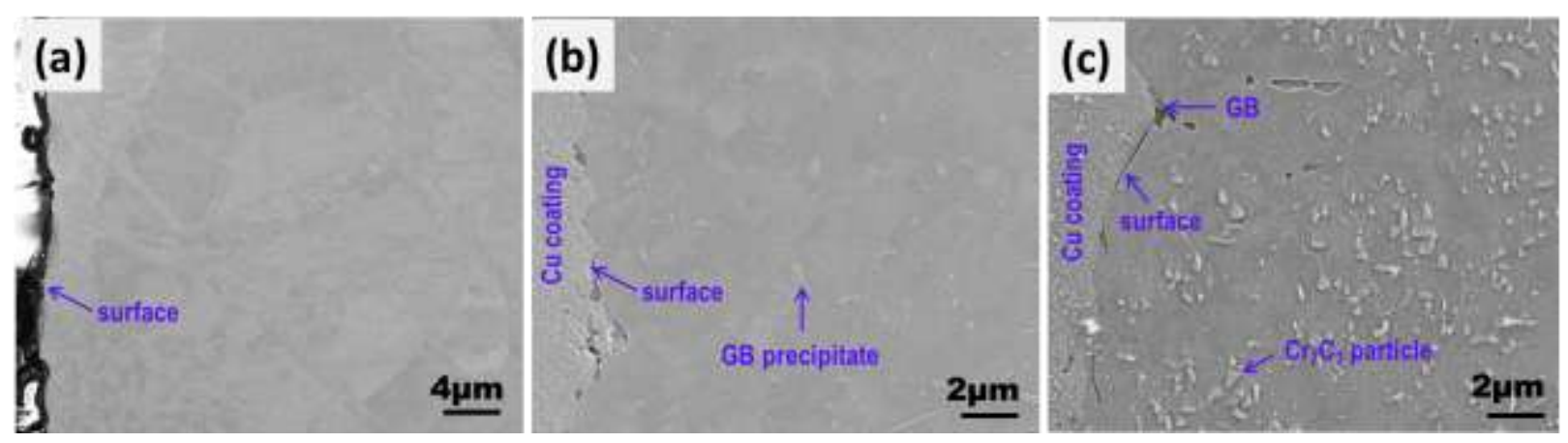

Figure 2: Cross-sectional SEM images of (a) the near-surface region of as-polished 316 stainless steel samples before corrosion tests, (b) near-surface region of the samples after 3000-hour tests in 316 stainless steel crucible and (c) near-surface region of the samples after 3000-hour tests in graphite crucible. 

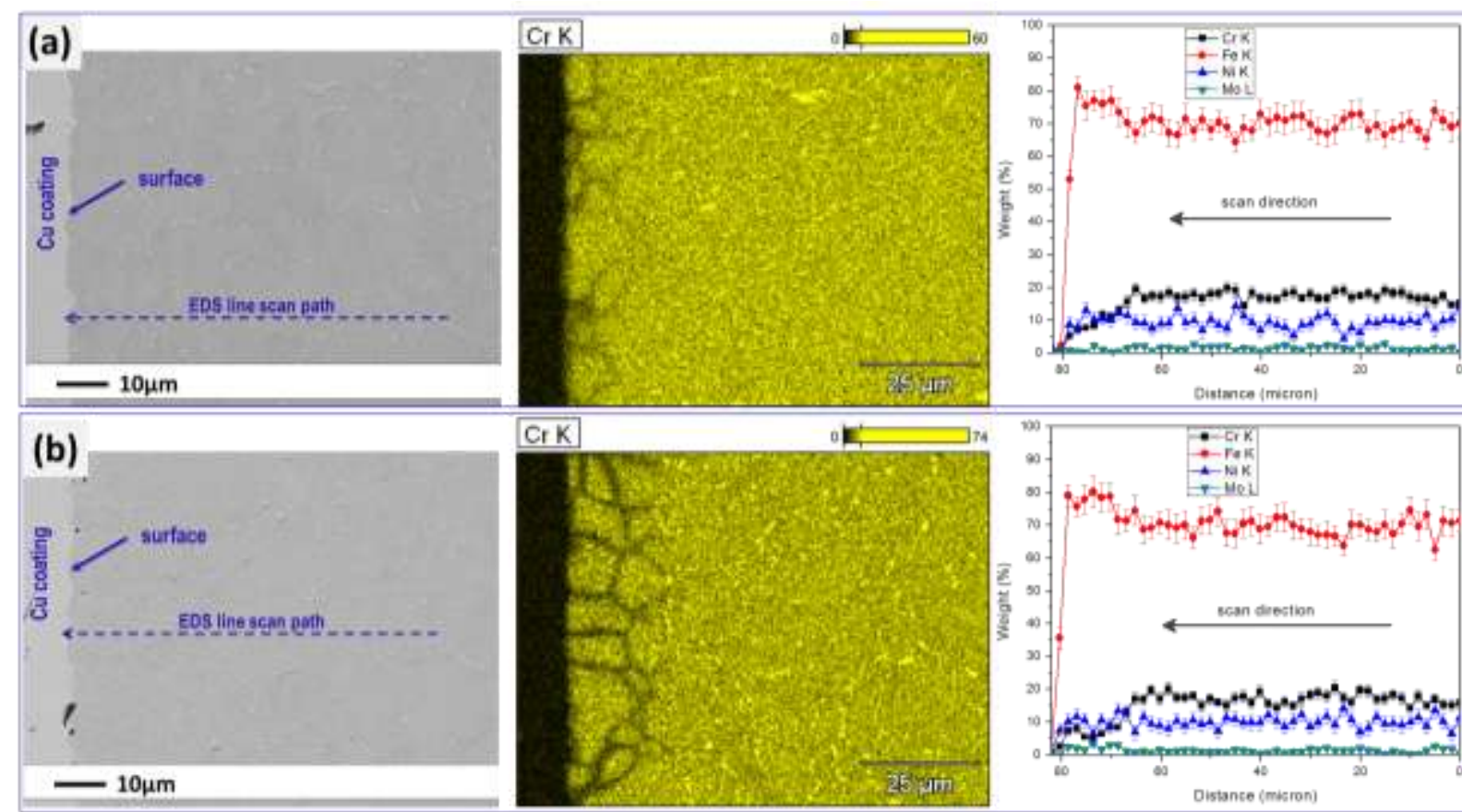

Figure 3: Cross-sectional SEM images, EDS Cr spectral images and the concentration profiles of the main elements $\mathrm{Cr}, \mathrm{Fe}$, Ni in the near-surface regions of the samples tested in (a) 316 stainless steel crucible and (b) in graphite capsule for 3000 hours. 

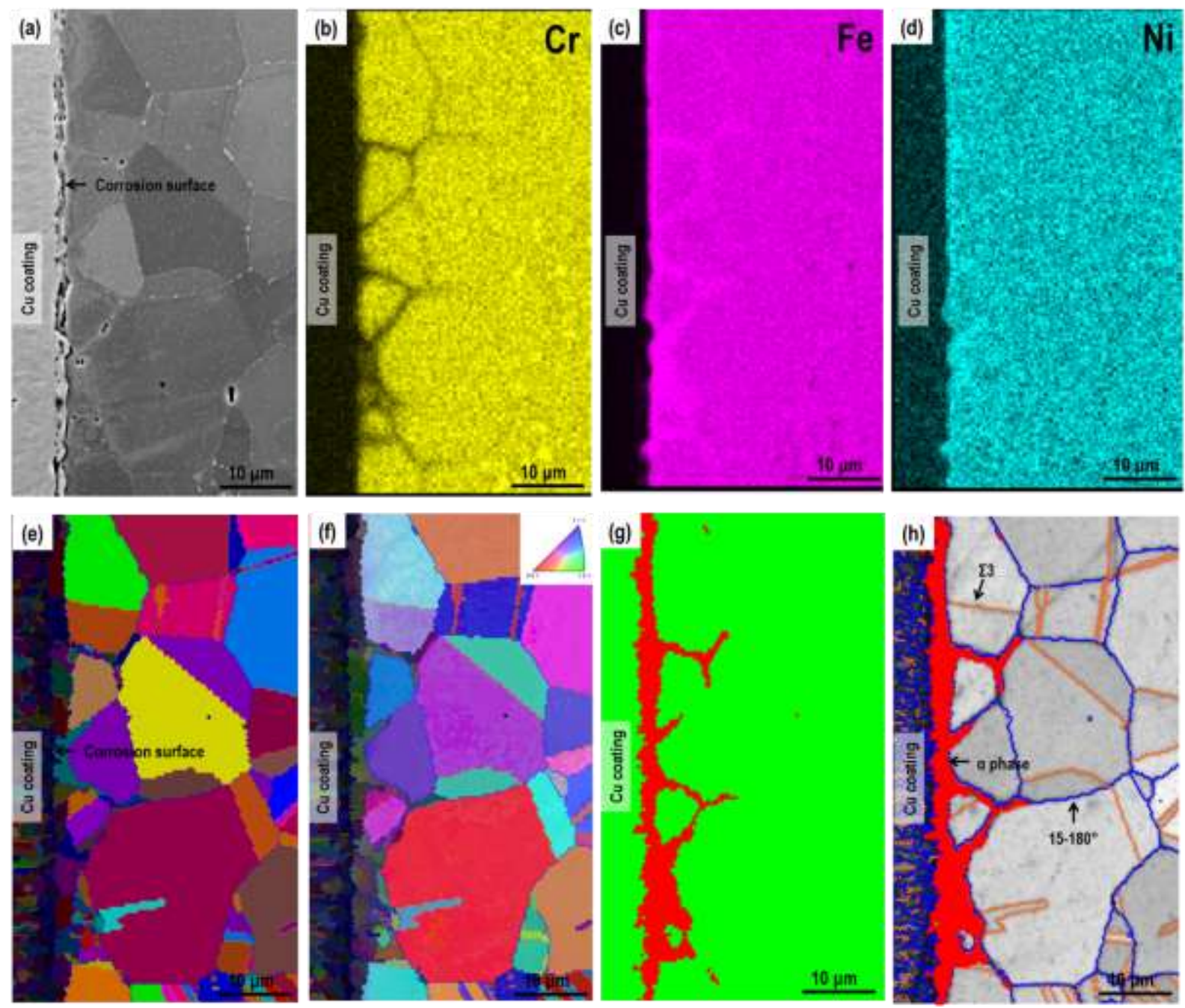

Figure 4: SEM cross-sectional examination of the near-surface regions of 316 stainless steel after 1000-hour exposure in molten FLiBe salt in a graphite crucible: (a) cross-sectional SEM image, (b-d) EDS element maps of $\mathrm{Cr}, \mathrm{Fe}$ and $\mathrm{Ni}$, and (e-h) EBSD maps. EBSD maps include (e) grain size distribution, (f) inverse polar figure (IPF), (g) iron $\alpha$ phase (red) distribution and (h) the images of grain boundary and $\alpha$ phase overlapped on image quality (blue lines and orange lines denote $15-180^{\circ}$ and $\Sigma 3$ grain boundaries, respectively). 

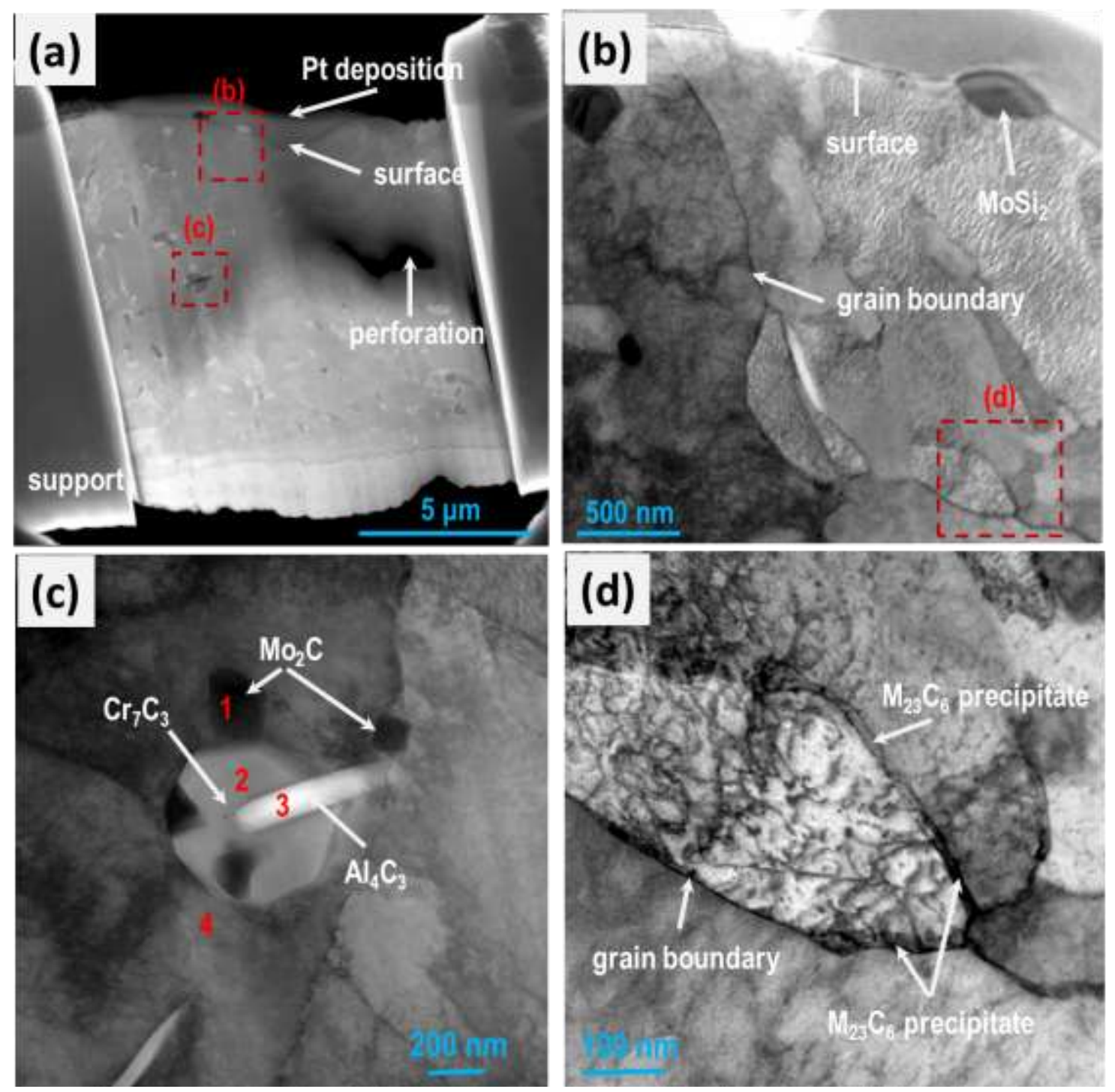

Figure 5: STEM images of a 316 stainless steel sample tested molten FLiBe in graphite crucible for 3000 hours, (a) high angle annular dark field (HAADF) image of a FIB lamella, (b) and (c) STEM bright-field images of a specific location framed in (a), and (d) a STEM bright-field image of a triple grain boundary junction framed in (b). 

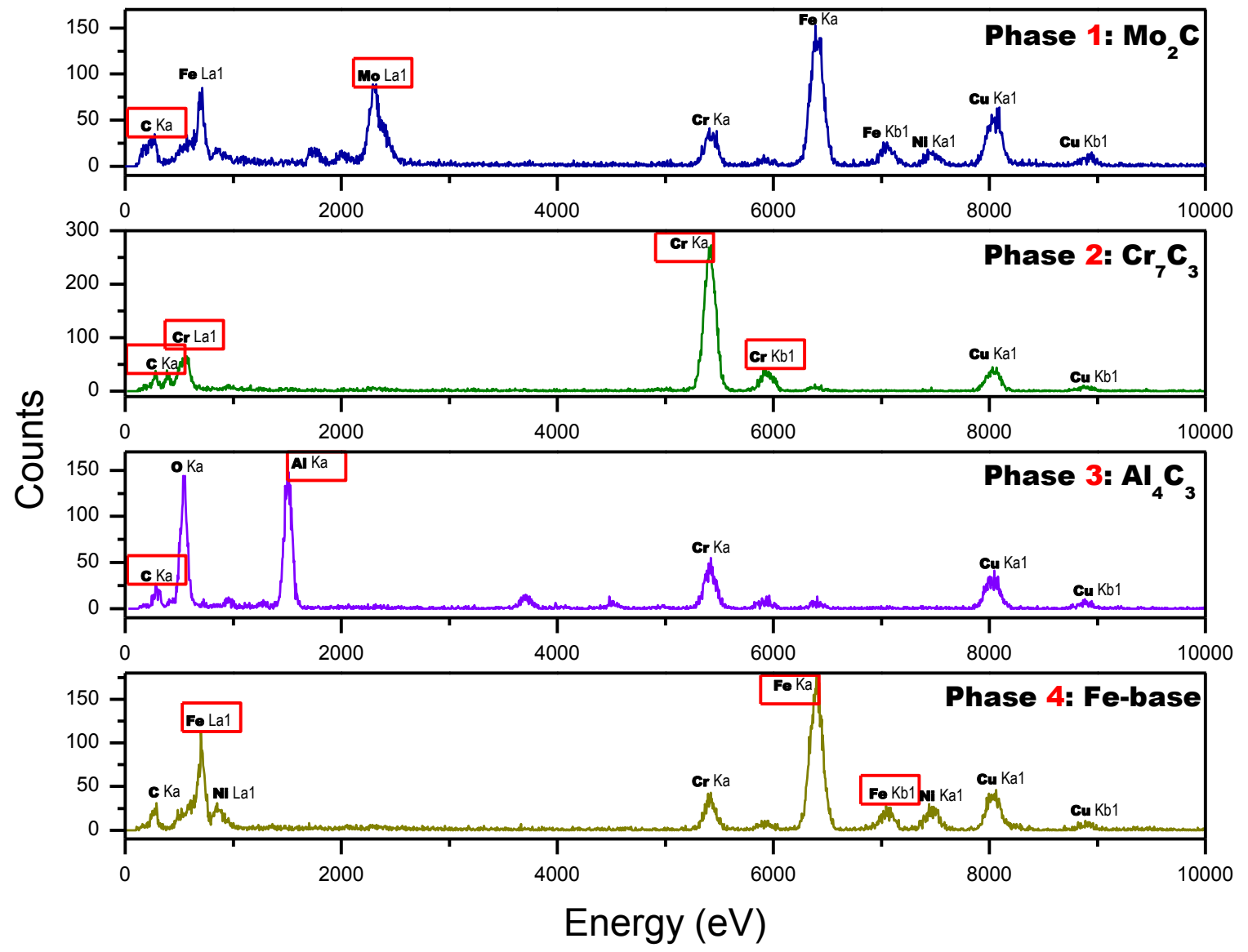

Figure 6: STEM-EDS compositional analysis spectra on the phases labeled in Figure 5(c) as 1, 2, 3, and 4. Main elements on each phase are highlighted by red frames. 

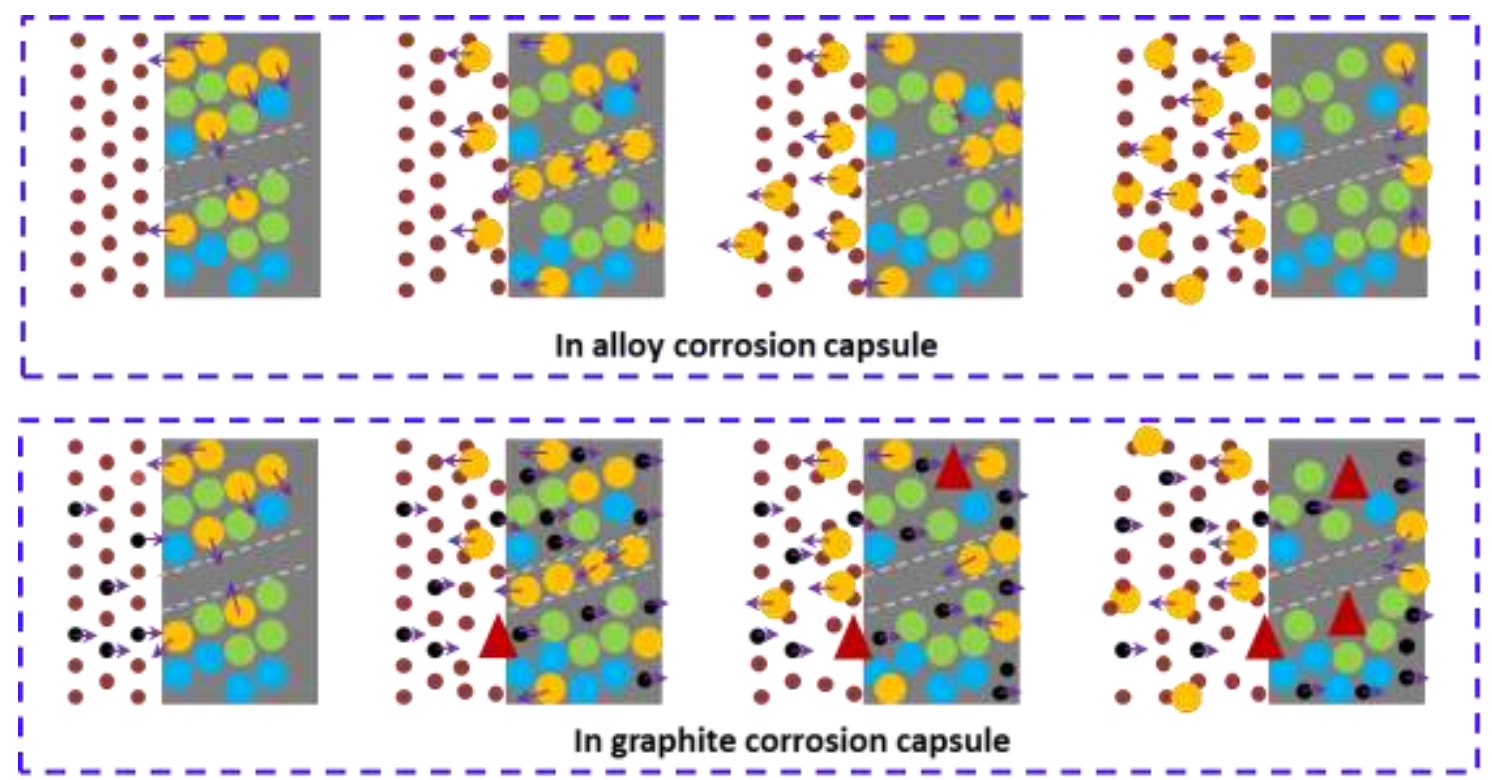

- $\mathrm{F} \bullet$ carbon $\odot \mathrm{Cr} \odot \mathrm{Fe} \odot \mathrm{Ni} \triangle$ carbide $\& \mathrm{CrF}_{2} \ldots, \ldots$ Grain boundary

Figure 7: Schematic illustration of the corrosion mechanisms of 316 stainless steel tested in molten FLiBe in 316 stainless steel crucible (top) and graphite crucible (bottom). 


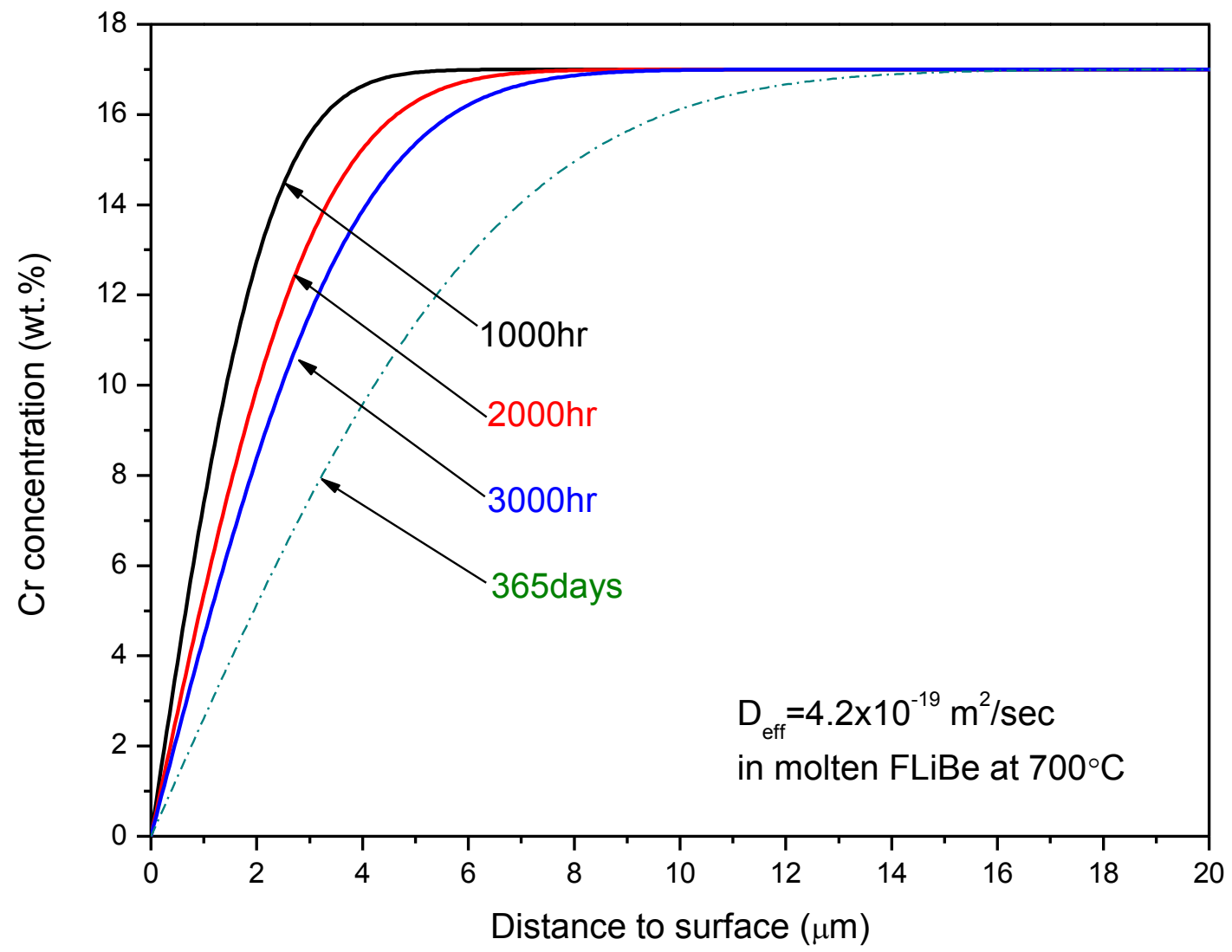

Figure 8: Calculated $\mathrm{Cr}$ concentration profiles for the 316 stainless steel tested in 316 stainless steel crucible in molten FLiBe salt at $700^{\circ} \mathrm{C}$ for 1000 hours, 2000 hours, 3000 hours. The expected profile for 1-year exposure is also shown. 


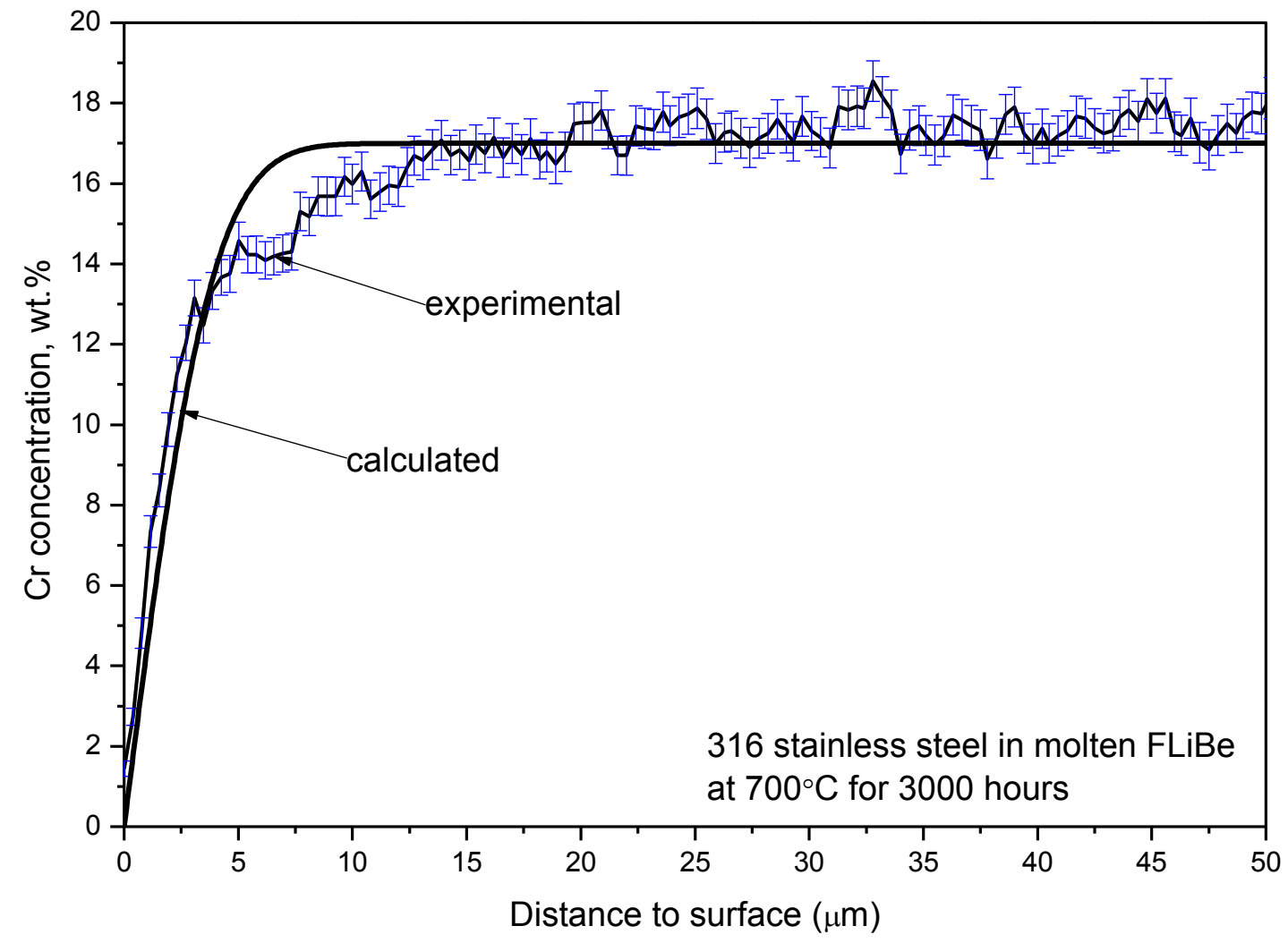

Figure 9: The experimental and calculated $\mathrm{Cr}$ concentration profiles for the 316 stainless steel tested in 316 stainless steel crucible in molten FLiBe for 3000 hours. 